\title{
Erratum to: Effectiveness of pharmaceutical care for drug treatment adherence in patients with systemic lupus erythematosus in Rio de Janeiro, Brazil: study protocol for a randomized controlled trial
}

\author{
M. Oliveira-Santos ${ }^{1,2}$
}

\section{Erratum}

After publication of our article [1], it was brought to our attention that there was an error in reference 35 . The correct reference is: de Oliveira-Filho AD, Morisky DE, Neves SJ, Costa FA, de Lyra DP Jr. The 8-item Morisky Medication Adherence Scale: validation of a Brazilian-Portuguese version in hypertensive adults. Res Soc Adm Pharm. 2014;10(3):554-61.

Received: 21 December 2016 Accepted: 21 December 2016

Published online: 02 March 2017

\section{Reference}

1. Oliveira-Santos M. Effectiveness of pharmaceutical care for drug treatment adherence in patients with systemic lupus erythematosus in Rio de Janeiro, Brazil: study protocol for a randomized controlled trial. Trials. 2016;17:181. 